\title{
Pregnancy with Fahr's Disease: A Rare Case report
}

\section{Introduction}

\author{
Ferhat GOKAY ${ }^{1}$, Yasin SIMSEK ${ }^{1}$, Ali YESILTEPE ${ }^{2}$, Oguzhan Sitki DIZDAR ${ }^{2}$ \\ 1. Kayseri Training and Research Hospital, Department of Endocrinology and Metabolism, Kayseri, Turkey \\ 2. Kayseri Training and Research Hospital, Department of Internal Medicine Kayseri, Turkey
}

Fahr's disease (FD) is a rare, neurological disorder characterized by abnormal calcified deposits in basal ganglia. The clinical characteristics are various and usually appears such as disfunction of the affected areas. According to our knowledge, no case of FD together with pregnancy has been described in the literature until now. The objective of this case report was to describe the clinical course of this rare condition in pregnancy

We reported 28-year-old pregnant woman with FD. She was diagnosed FD by using physical, laboratory and radiological examination 3 years ago. Cranial computed tomography (CT) showed bilateral symmetric calcifications in the caudate and lentiform nuclei, thalamus and cerebral gyrus as shown in Figure 1. She had no complaint about neurological, endocrinological and laboratory examinations showed normal limits of whole blood counts, renal, liver function tests, serum calcium, phosphorus, magnesium, alkaline phosphatase, parathyroid hormone, $25 \mathrm{OH}$ D3 and thyroid hormones during pregnancy (Table 1). Her pregnancy was uneventful until the day of delivery.

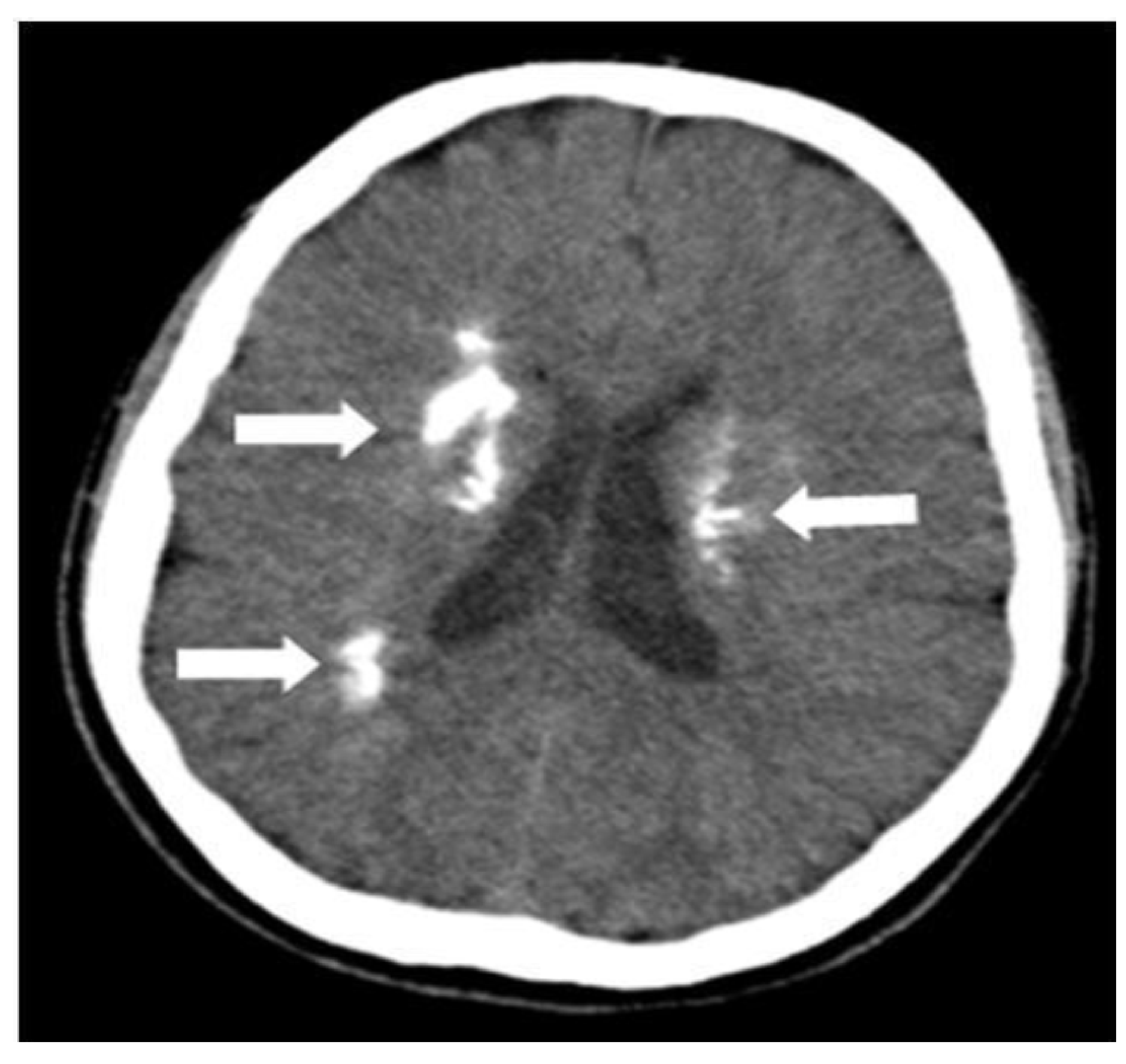

Figure 1: Cranial computed tomography images showing calcification in the brains of patients with Fahr's disease.
Table 1: Laboratory examinations of the patient

\begin{tabular}{lccc}
\hline Serum parameters & $\begin{array}{c}\text { 4. week of } \\
\text { pregnancy }\end{array}$ & $\begin{array}{c}\text { 38. week of } \\
\text { pregnancy }\end{array}$ & Normal range \\
\hline Ure/creatinin & $21 / 0,7$ & $20 / 0,8$ & $(7-20) /(0,6-1,3 \mathrm{mg} / \mathrm{dL})$ \\
Sodium/potassium & $138 / 4,2$ & $137 / 4,3$ & $(135-145) /(3,5-5 \mathrm{mmol} / \mathrm{L})$ \\
Calcium/phosphorus & $9,6 / 4,2$ & $9,7 / 3,9$ & $(8,4-10,6) /(2,3-4,7 \mathrm{mg} / \mathrm{dL})$ \\
Magnesium & 1,9 & 2,1 & $(1,5-2,5 \mathrm{mg} / \mathrm{dl})$ \\
SGPT/SGOT & $21 / 28$ & $28 / 34$ & $(<35) /(<35 \mathrm{U} / \mathrm{L})$ \\
\hline Parathyroid hormone & 45 & - & $(15-88 \mathrm{pg} / \mathrm{mL})$ \\
TSH & 2,1 & 2,4 & $(0,4-5,6 \mathrm{mIU} / \mathrm{L})$ \\
fT4 & 0,9 & 0,7 & $(0,54-1,24 \mathrm{ng} / \mathrm{dL})$ \\
25 OH D3 & 31 & 32 & $(>30 \mathrm{ng} / \mathrm{mL})$ \\
Hemoglobine & 13 & 12 & $(12-16 \mathrm{gr} / \mathrm{dL})$ \\
\hline
\end{tabular}

\section{Conclusions}

Fahr's disease may not negative effect the pregnancy. However, in this regard, series of cases are needed.
References
1. Lazăr M, Ion DA, Streinu-Cercel A, Bădărău AI. Fahr's syndrome: Diagnosis issues in patients with unknown family history of disease. Rom J Morphol Embryo. 2009; 50:425-428

2. Shenoy AM, Volpe D, Ensrud ER. Fahr's disease. Practical neurology. 2009; 9:100-101 